\title{
BENZYLISOQUINOLINE BIOSYNTHESIS BY CULTIVATED PLANT CELLS AND ISOLATED ENZYMES. ${ }^{1}$
}

\author{
Meinhart H. Zenk*, Martina Rueffer, Manfred AmanN, Brigitte Deus-Neumann,
} Lebrstubl für Pharmazeutische Biologie, Universität München, Karlstrasse 29, D-8000 München 2, West Germany and NAOTAKa NAGakURA

Kobe Women's College of Pharmacy, Kobe 658, Japan

\begin{abstract}
Plant cell cultures rather than differentiated plants are the preferred material for studying secondary product formation and elucidate the enzyme pathways responsible for isoquinoline alkaloid formation. Using callus and cell suspension cultures of different Berberis species, we studied the incorporation of early precursors like tyrosine, dopa, tyramine, and dopamine into jatrorrhizine. Besides tyrosine, tyramine and, to a lesser extent, dopamine were incorporated into the aldehyde precursor moiety of the isoquinoline molecule. The use of cellfree extracts of Berberis cultures has allowed us to isolate and characterize all of the eight enzymes involved in berberine biosynthesis. (S)-Tetrahydroprotoberberine oxidase was successfully immobilized and could be used for the quantitative conversion of $(S)$-tetrahydroprotoberberines through their dehydroderivatives and their racemic reduction products into the pure $(R)$-enantiomer. This latter enzyme and the berberine bridge enzyme are localized exclusively in a new vesicle with the density $\delta=1.14$; all six other enzymes of the pathway are cytoplasmic. Using highly labeled $(R)$ - and $(S)$-reticuline as well as scoulerine, it could be demonstrated that the transport of these compounds into vacuoles of Fumaria capreolata does not proceed by an ion-trap mechanism, but rather involves an active ATP-requiring, stereospecific carrier system acting only on the $(S)$ - and not on the $(R)$-enantiomer.
\end{abstract}

The benzylisoquinoline alkaloid series shows an unusually rich variety of structural types $(1,2)$. Many useful biogenetic schemes have been suggested (summarized in 3) to account for the biosynthesis of these molecules. Remarkable progress was made in the 1960 s and 1970s in elucidating these pathways using living differentiated whole plants and various precursor molecules labeled with radioactive or stable isotopes. However, as was pointed out already by I.D. Spenser as early as 1968 (4), more reliable information on the actual biosynthetic sequences can only be obtained by in-vitro work with the purified enzymes of biosynthesis. Tracer work only suggests probable biosynthetic sequences; the ultimate proof, however, can only be given by the isolation and characterization of the respective catalysts. In addition, more information has to be sought and gained on the compartmentation of enzymes involved in the biosynthetic chain leading to secondary plant products and on the mechanisms by which these products and their precursors are transported and stored. Because of the structural diversity expressed in the benzylisoquinoline group, and due to the pharmaceutical value that some of its members (e.g., codeine, berberine, galanthamine, hydrastine, morphine, narcotine, tetrandrine, $\alpha$-tubocurarine) represent, biosynthetic work on these compounds is justified in addition to its heuristic value.

Cell Cultures.-Cell suspension as well as callus cultures of several species of the families Berberidaceae, Ranunculaceae, Menispermaceae, Papaveraceae, and Fumariaceae produce isoquinoline alkaloids in substantial amounts (5). The most diverse isoquinoline alkaloid spectrum for a cell suspension culture thus far published has been found to occur in Fumaria capreolata (6). The structural types of benzylisoquinoline alkaloids found in cell cultures indicating also their biogenetic relationship are shown

'Presented as a plenary lecture at the "Biologically Active Nitrogen-Containing Natural Products: Structure, Biosynthesis, and Synthesis" Symposium of the International Research Congress on Natural Products at the University of North Carolina, Chapel Hill, North Carolina, July 7-12, 1985. 
in Figure 1. All of these structures have been isolated and identified in callus and/or suspension cultures except for cularine- and pavine-type alkaloids, which have not yet been found to occur in undifferentiated plants. Plant cell cultures capable of producing the desired alkaloids are excellent sources of enzyme systems (7). Cells can be grown under exactly defined conditions on a large scale, thus providing any desired amount of homogeneous plant material as an enzyme source independent of seasons. As a rule, levels of enzyme activity are considerably higher in suspension cells as compared with whole plants because the time required for product synthesis under cell culture conditions is much shorter than in field-grown plants. In differentiated plants, stationary levels of enzymes involved in secondary metabolism seem to be very low in general. The high content of phenolics and other undesirable cell constituents tends to inactivate enzymes during the isolation procedure. By using plant cell cultures, however, it has been possible to gain a deeper insight into the cell-free biosynthesis of benzylisoquinoline alkaloids $(7,8)$.

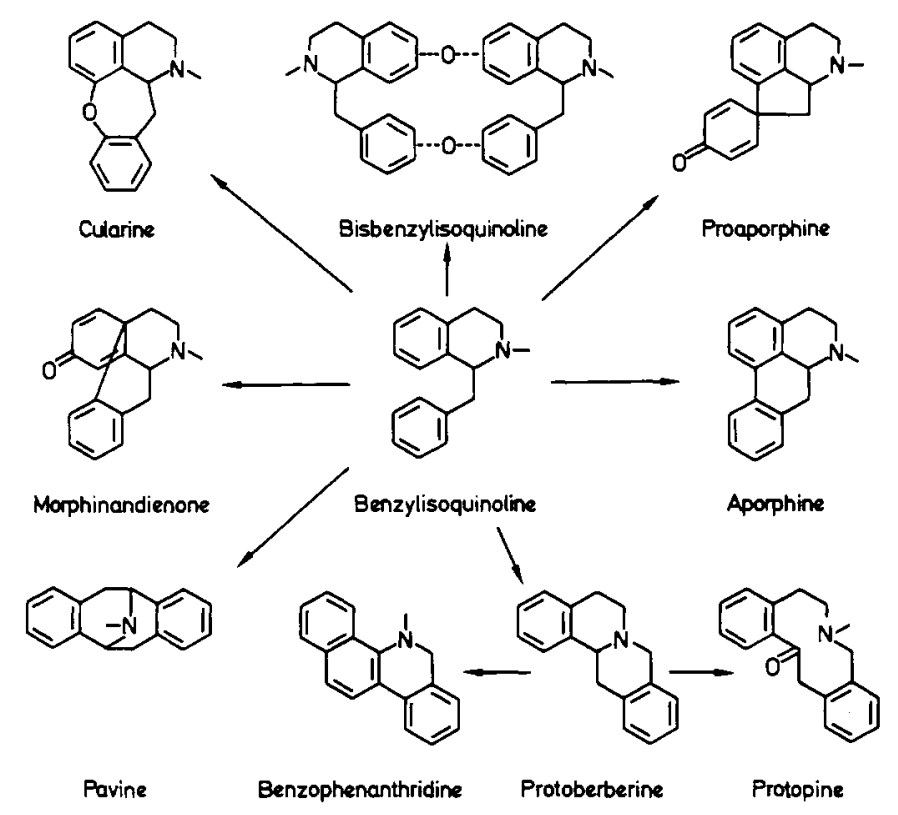

Figure 1. Structural types of benzylisoquinoline alkaloids found in plant cell cultures indicating also their biogenetic relationship. Cularine and pavine type alkaloids have not been detected so far in cell cultures.

THE DISTANT PRECURSORS.-As early as 1910, Winterstein and Trier (9) suggested that two molecules of 3,4-dihydroxyphenylalanine (DOPA) might be modified in the plant to yield dopamine and 3,4-dihydroxyphenylacetaldehyde, which in turn could condense and yield norlaudanosoline, recognized already at that time as a potential precursor for more complex isoquinoline alkaloids. Gear and Spenser (10) were the first to observe that singly-labeled tyrosine (a known precursor of DOPA) can serve as a specific precursor of hydrastine and that the two units forming this benzylisoquinoline alkaloid bear labels to a different extent. Further work, (4) established beyond doube that tyrosine contributes to the upper (isoquinoline) as well as to the lower (benzyl) portion of these alkaloids, whereas DOPA, formed from tyrosine, is exclusively incorporated into the isoquinoline moiety (Figure 2). The nature of the true precursors during the formation of the benzylisoquinoline system has not been fully 


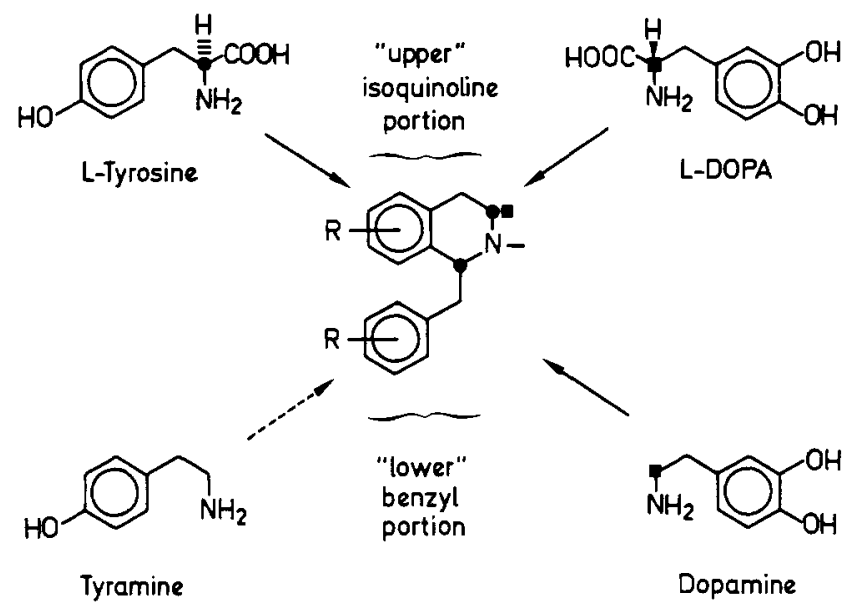

FIGURE 2. Incorporation experiments described in the literature (4) using ${ }^{14} \mathrm{C}$-labeled potential precursors resulting in different labeling of the upper, isoquinoline, and the lower, benzyl, portion of benzylisoquinoline alkaloids.

established yet (11). 3,4-Dihydroxyphenylpyruvic acid, which has been postulated as an intermediate in benzylisoquinoline biosynthesis through the formation of norlaudanosoline-1-carboxylic acid (12), has been ruled out by enzyme work (13). It is quite certain that dopamine is the precursor of the upper (isoquinoline) portion of these alkaloids. It is formed from tyrosine via DOPA and subsequent decarboxylation (Figure $3)$.

The question remains how the precursor of the benzylic portion of norlaudanosoline, now known to be 3,4-dihydroxyphenylacetaldehyde (13), is formed.
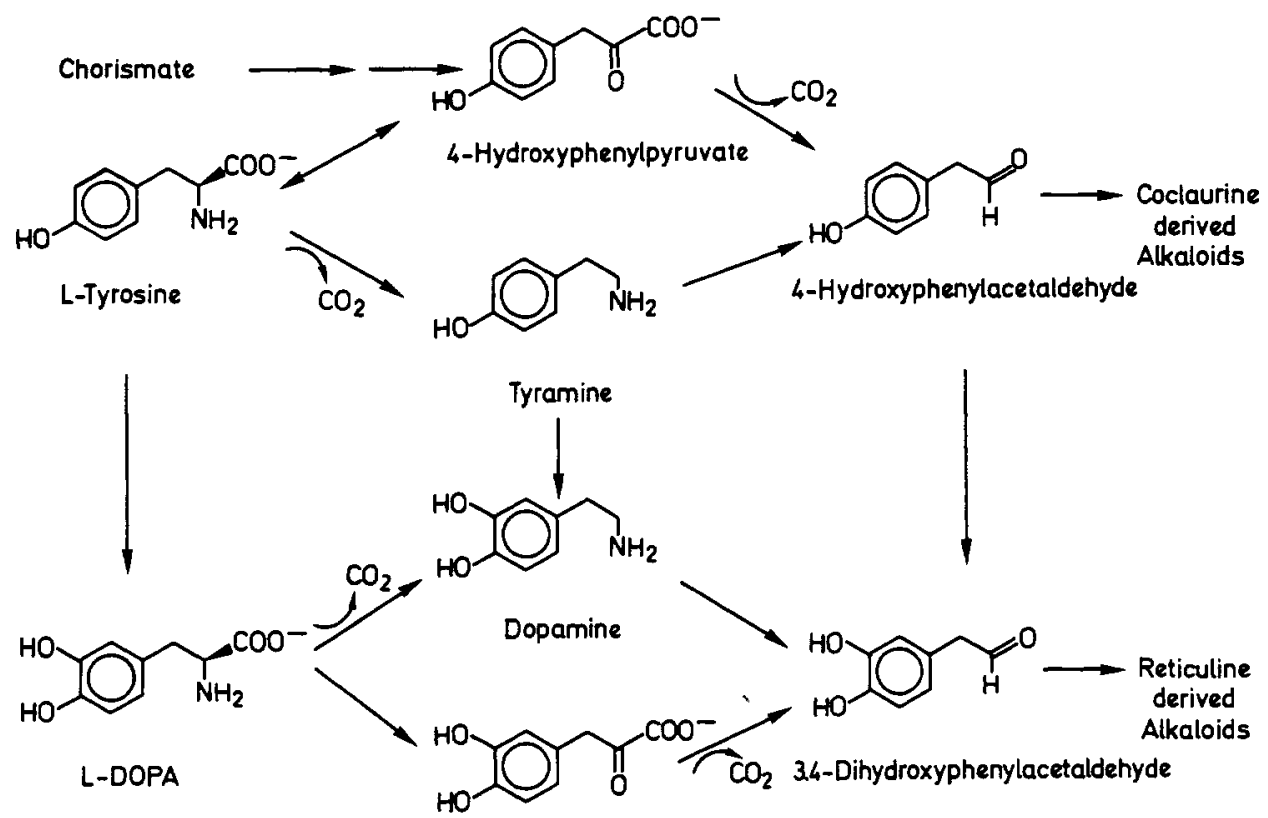

3.4 Dihydroxyphenylpyruvate

FIGURE 3. Biosynthetic sequence leading from a primary metabolite (tyrosine) to the building blocks of the benzylisoquinoline alkaloids: dopamine, 3,4-dihydroxyphenylacetaldehyde, and 4-hydroxyphenylacetaldehyde. 
Three possibilities are shown in Figure 3. 4-Hydroxyphenylacetaldehyde is formed either by decarboxylation of 4-hydroxyphenylpyruvate or by action of a monoamine oxidase on tyramine, and can then be hydroxylated by action of a phenolase to yield the dihydroxy precursor. The two other possibilities comprise the deamination of dopamine or the decarboxylation of 3,4-dihydroxyphenylpyruvate by a plant enzyme to yield the dihydroxylated aldehyde. To investigate these possibilities, all four potential precursors labeled in the 1 '-position were administered to rapidly growing callus cultures of Berberis canadensis. Jatrorrhizine, the major alkaloid of this species (14), was isolated, methylated to palmatine, and subsequently subjected to permanganate oxidation (15) yielding the upper and lower halves of the protoberberine molecule. Incorporation and degradation data are summarized in Table 1.

TABLE 1. Incorporation of Potential Precursors into Jatrorrhizine by Callus Cultures of Berberis canadensis

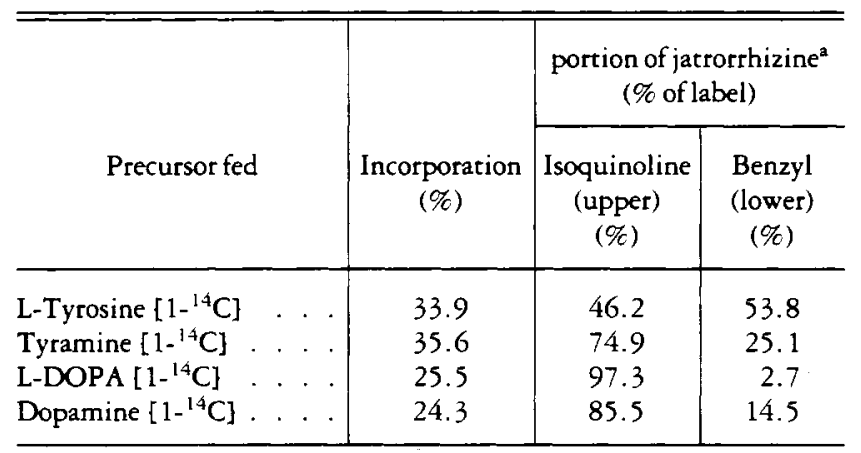

${ }^{a}$ The protoberberine molecule was methylated and cleaved into the upper isoquinoline and the lower benzyl portion, and the distribution of radioactivity was determined.

The incorporation of all four precursors into the protoberberine was between 25 and 35 percent. The incorporation of tyrosine into both halves of the protoberberine follows the classical pattern established earlier (4). The incorporation of tyramine into both halves of the protoberberine molecule, however, demonstrates beyond doubt that the suggested condensation of dopamine and 3,4-dihydroxyphenylpyruvate affording the intermediate norlaudanosoline-1-carboxylic acid (12) is not an important pathway, if it occurs at all. Surprisingly, dopamine is also incorporated to an extent of 14 percent into the lower portion of the protoberberine molecule, while DOPA itself is almost exclusively incorporated into the upper isoquinoline portion of the target molecule, confirming the well-established biosynthetic scheme (e.g., 4).

For the interpretation of these results, it is important to realize that large pools of dopamine have been discovered to occur in Papaver somniferum, which are, in addition, compartmentalized in different cellular and subcellular loci (16). This dopamine pool could lead to an enormous dilution of the labeled precursor administered, resulting in a low absolute incorporation. Furthermore, any monoamine oxidase acting on this dopamine pool to yield the required $\mathrm{C}_{6}-\mathrm{C}_{2}$ precursor would further reduce the labeling of the benzyl (lower) unit of morphinan alkaloids. In contrast, only a small dopamine pool has been observed in $B$. canadensis callus, which might explain the results obtained in the DOPA and dopamine feeding (and degradation) experiments (Table 1; Figure 4). Both dihydroxylated precursors, in contrast to other feeding experiments-expertly discussed by Holland, et al. (11)-label both halves of the benzylisoquinoline molecule, although to an unequal extent. Tyramine, whose incorporation into the isoquinoline as well as the benzyl portion of a protoberberine alkaloid, has been ob- 


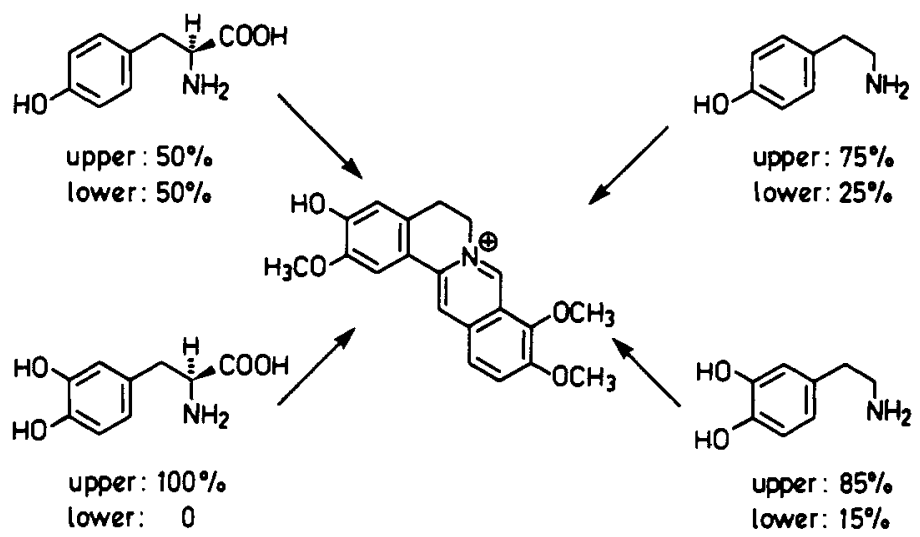

FIGURE 4. Incorporation of ${ }^{14} \mathrm{C}$-labeled potential precursors into the isoquinoline "upper" and the benzyl "lower" portion of the protoberberine molecule jatrorrhizine, produced by Berberis canadensis callus tissue.

served here for the first time, but has been used surprisingly little in biosynthetic experiments in the past, (11).

As a result, we have to assume that tyrosine is not metabolized solely via DOPA. DOPA seems to be converted predominantly to dopamine by decarboxylation, which serves as precursor for the upper portion of the benzylisoquinoline system. Some dopamine is converted also by deamination to 3,4-dihydroxyphenylacetaldehyde. The main portion of the benzyl precursor is, however, formed from tyramine by deamination and subsequent hydroxylation of the 4-hydroxyphenylacetaldehyde thus formed. Monoamine oxidase acting on both tyramine and dopamine, and phenolase activity hydroxylating all three substances (tyramine, tyrosine, and 4-hydroxyphenylacetaldehyde) are also present in the cells. The latter enzyme was discovered in crude extracts of the Berberis cell culture purified, and its properties were then studied (17). There was also evidence for some weak activity decarboxylating $p$-hydroxyphenylpyruvate to yield $p$-hydroxyphenylacetaldehyde (17). In the past, internal pool sizes of metabolites and compartments in which some of these enzymes are located (17) have certainly influenced the interpretation of feeding and incorporation experiments conducted with distant precursors of isoquinoline alkaloids (4). We now regard the link between primary metabolism (tyrosine, DOPA) and secondary metabolism (dopamine, 3,4-dihydroxyphenylacetaldehyde) as largely understood.

ENZYMES AND INTERMEDIATES. - The final aim in elucidating a metabolic pathway is the isolation and characterization of the individual enzymes catalyzing the stepwise transformation of the primary precursors to the ultimate products. During the past years, we have been able to isolate all four enzymes involved in the synthesis of ( $S$-reticuline, a central intermediate in benzylisoquinoline biosynthesis (Figure 5). The first enzyme in this biosynthetic pathway is $(S)$-norlaudanosoline synthase, which we discovered in cell-free systems from representatives of ten different genera from three plant families $(13,18)$. This novel enzyme condenses dopamine with 3,4-dihydroxyphenylacetaldehyde to yield norlaudanosoline directly. The aldehyde, rather than the previously postulated 3,4-dihydroxyphenylpyruvate, is the substrate for this condensation reaction. The reaction product was proven to possess the $1-\alpha-\mathrm{H}-(S)$ configuration. There was, however, a considerable amount of nonenzymatic condensation of aldehyde with amine taking place under the incubation conditions, yielding racemic norlaudanosoline.

This first intermediate in the reticuline pathway is $O$-methylated predominantly in 


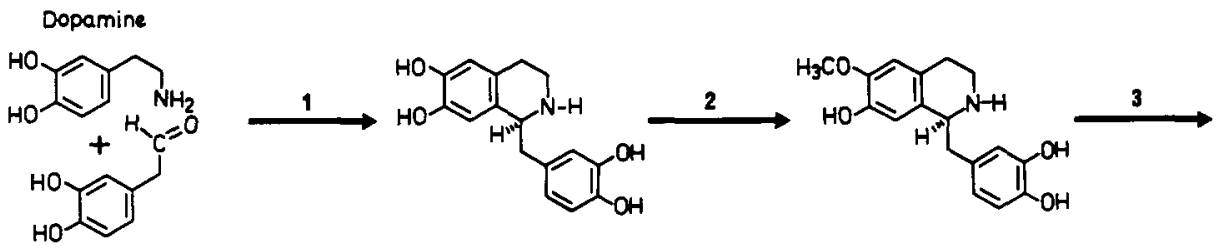

3,4-Dihydroxyphenylacetaldehyde
(S)-Norlaudanosoline

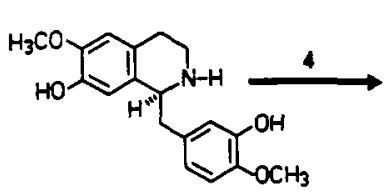

(S)-Norreticuline

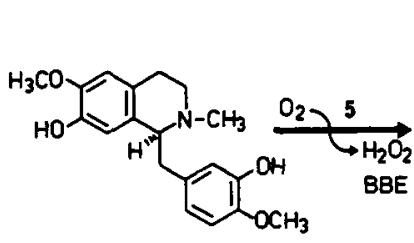

(S)-Reticuline
(S)-6-Methylnorlaudanosoline

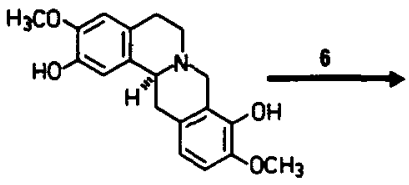

(S)-Scoulerine

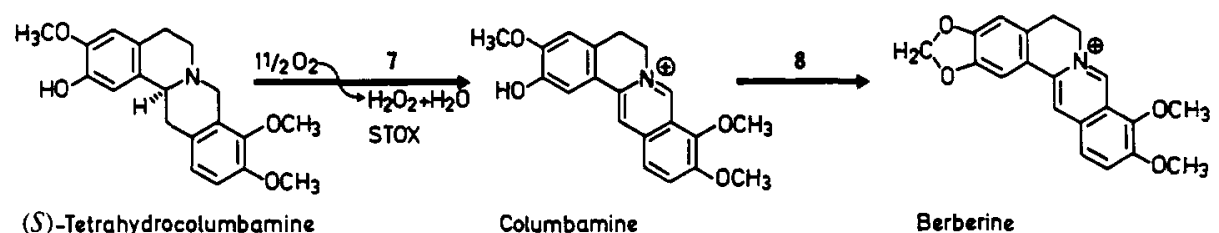

FIGURE 5. The biosynthetic pathway to berberine involving eight different enzymes that were isolated and characterized from protoberberine-containing cell suspension cultures.

the 6 position, $S$-adenosyl-L-methionine (SAM) being the methyl group donator. The enzyme catalyzing this reaction was found to occur in serveral species of four families, all containing isoquinoline alkaloids. This enzyme does not distinguish between $(R)$ and $(S)$-norlaudanosoline, and besides about 80 percent of $6-0$-methylnorlaudanosoline, about 20 percent of 7-0-methylnorlaudanosoline is formed (19). 6-OMethylnorlaudanosoline is further modified by an enzyme that specifically methylates the $4^{\prime}-\mathrm{OH}$ group of this intermediate to yield norreticuline. This enzyme, which is presently being investigated in our laboratory by $\mathrm{T}$. Frenzel, is highly stereospecific in that it only utilizes the substrate with the $(S)$-configuration. The final step in the biosynthesis of reticuline is the $N$-methylation of norreticuline. This new enzyme was discovered (20) in a number of species belonging to the genera Berberis, Corydalis, Eschscboltzia, Fumaria, and Thalictrum. The $N$-methyltransferase has a rather broad substrate specificity in that it methylates several differently substituted norbenzylisoquinoline alkaloids. The enzyme is also not stereospecific in that it uses both $(R)$-and $(S)$-isomers. This enzyme, in combination with isotopically labeled SAM and stereochemically pure $(R)$ - or $(S)$-norreticuline as substrate, can provide the respective reticuline species with extremely high specific activities for use in biosynthetic or enzymatic experiments.

$(S)$-Reticuline is the main branch point intermediate in the biosynthesis of isoquinoline alkaloids. The molecule is able to undergo many different transformations to yield the structural diversity of alkaloids depicted in Figure 1. One of these possibilities is the formation of protoberberine alkaloids. The first enzyme, which is the only one in this pathway that had previously been detected and purified sevenfold from cell cultures of Macleaya (21), is responsible for the formation of the berberine bridge. We have devised a new assay system for this enzyme (22), which relies on the use of $N$ $\mathrm{CT}_{3}-(S)$-reticuline as substrate. The conversion of this labeled substrate to scoulerine, the established product of the berberine bridge enzyme (BBE) $(21,22)$, results in the release of exactly one-third of the radioactivity of the $N$-methyl label into the aqueous phase of the incubation mixture. This enzyme was found to occur in more than 50 dif- 
ferentiated plants and cell cultures. It was purified to homogeneity and characterized (Table 2). The previously postulated $(S)$-reticuline- $N$-oxide is neither a substrate nor an intermediate in this reaction. Besides scoulerine, stoichiometric amounts of $\mathrm{H}_{2} \mathrm{O}_{2}$ are produced by the BBE. A second enzyme acts on scoulerine as substrate (23). It is a new methyltransferase which catalyzes the stereospecific and regiospecific 0 -methylation at position 9 of $(S)$-scoulerine using SAM as methyl group donor (Figure 5). This enzyme transforms $(S)$-scoulerine to $(S)$-tetrahydrocolumbamine. This product is next transformed into the protoberberine columbamine by the specific oxidation of ring $C$ by a new enzyme, (S)-tetrahydroprotoberberine oxidase (abbreviated STOX) (24), which

TABLE 2. Some Properties of the Eight Enzymes Involved in Berberine Biosynthesis, Indicating also Source of Cell Cultures used for Isolation of Each Enzyme

\begin{tabular}{|c|c|c|c|c|c|c|c|}
\hline No. & Name $^{a}$ & $\begin{array}{l}\text { Plant } \\
\text { source }\end{array}$ & $\begin{array}{l}\text { Purification } \\
\text { factor } \\
\text { (-fold) }\end{array}$ & $\begin{array}{c}\mathrm{pH}- \\
\text { (optimum) }\end{array}$ & $\begin{array}{l}\text { Molecular } \\
\text { weight } \\
\text { (kD) }\end{array}$ & $\begin{array}{l}\text { Particle } \\
\text { bound }\end{array}$ & $\begin{array}{c}\text { Stereo } \\
\text { specificity }\end{array}$ \\
\hline 1 & $\begin{array}{l}\text { Norlaudanosoline } \\
\text { Synthase }\end{array}$ & $\begin{array}{l}\text { Eschicboltzia } \\
\text { tenuifolia }\end{array}$ & 40 & 7.8 & 15 & No & Yes \\
\hline 2 & 6-O-Methyltransferase & $\begin{array}{l}\text { Argemone } \\
\text { platyceras }\end{array}$ & 80 & 7.5 & 47 & No & No \\
\hline 3 & $4^{\prime}-0$-Methyltransferase & $\begin{array}{l}\text { Glaucium } \\
\text { rubrum }\end{array}$ & 40 & 7.5 & 68 & No & Yes \\
\hline 4 & N-Methyltransferase & $\begin{array}{l}\text { Berberis } \\
\text { tulgaris }\end{array}$ & 100 & 7.7 & 68 & No & No \\
\hline 5 & $\begin{array}{l}\text { Berberine Bridge Enzyme } \\
\text { (BBE) }\end{array}$ & $\begin{array}{l}\text { Berberis } \\
\text { beaniana }\end{array}$ & $\begin{array}{l}\text { homo- } \\
\text { geneous }\end{array}$ & 8.9 & 49 & Yes & Yes \\
\hline 6 & $\begin{array}{l}\text { Scoulerine-9-0- } \\
\text { methyltransferase }\end{array}$ & $\begin{array}{l}\text { Berberis } \\
\text { uilsoniat } \\
\text { iar.subcaulialata }\end{array}$ & 27 & 8.9 & 63 & No & Yes \\
\hline 7 & $\begin{array}{l}\text { (S)-Tetrahydroproto- } \\
\text { berberine Oxidase (STOX) }\end{array}$ & $\begin{array}{l}\text { Berberis } \\
\text { uilsoniate } \\
\text { tar, subiaulialata }\end{array}$ & $\begin{array}{l}\text { homo- } \\
\text { geneous }\end{array}$ & 8.9 & 100 & Yes & Yes \\
\hline 8 & Berberine Synthase & $\begin{array}{l}\text { Berberis } \\
\text { stolonifera }\end{array}$ & $\begin{array}{l}\text { homo- } \\
\text { geneous }\end{array}$ & 8.9 & 32 & - & b \\
\hline
\end{tabular}
pathway.

${ }^{2}$ Enzymes No. $1-4$ belong to the general $(S)$-reticuline pathway; Enzymes No. 5-8 are part of the protoberberine

${ }^{b}$ No asymmetric center in the molecule.

catalyzes the dehydrogenation of more than 20 different tetrahydroprotoberberines, including canadine, capaurimine, coramine, coreximine, corydaline, corydalmine, corypalmine, discretamine, isocorypalmine, methoxycorytenchirine, tetrahydropalmatrubine, scoulerine, stepholidine, stylopine, and tetrahydropalmatine. The enzyme is absolutely specific for the substrate with the $(S)$-configuration. The enzyme was purified to homogeneity and characterized: It is a flavine enzyme producing 1 mole $\mathrm{H}_{2} \mathrm{O}_{2}$ per mole of substrate under consumption of oxygen. Later, our enzyme was also detected in crude callus homogenates by Beecher and Kelleher (25). Their claim that tetrahydrojatrorrhizine is not a substrate for this enzyme is incorrect. Using authentic substrate (by ms, nmr) and enzyme from Berberis aggregata [a species that has been used by these authors (25)], it can be seen in Figure 6 that tetrahydrojatrorrhizine is also an excellent substrate for the enzyme from this plant. The suggested reaction mechanism for the oxidation of tetrahydroisoquinolines is given by Amann et al. (24).

Columbamine thus formed is further transformed by another enzyme to yield berberine. This reaction involves the formation of a methylenedioxy ring. The enzyme catalyzing this reaction has been purified to homogeneity from Berberis stolonifera (26). It is an $\mathrm{Fe}^{++}$-containing enzyme with a surprisingly high temperature optimum $\left(70^{\circ}\right)$ and is the first enzyme found to form a methylenedioxy ring from a methoxy group adjacent to a phenolic hydroxyl (Figure 5). This enzyme completes the sequence of four 


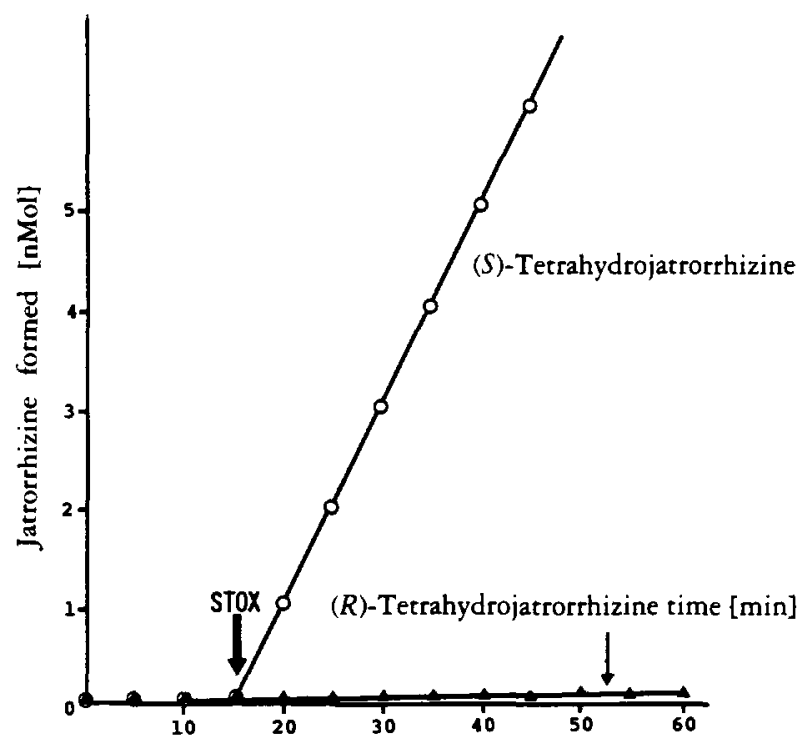

FIGURE 6. Oxidation of (S)-tetrahydrojatrorrhizine by STOX. Jatrorrhizine formation was photometrically monitored at $369 \mathrm{~nm}$ and calculated with $\epsilon_{369}^{\mathrm{PH}}=25.2 \times 10^{6} \mathrm{~cm}^{2} \mathrm{~mol}^{-1}$. The borate buffered (0.05 M, pH 8.9) incubation mixture $(0.7$ $\mathrm{ml}$ ) contained $40 \mu \mathrm{M}$ substrate and $0.1 \mathrm{ml}$ enzyme preparation $\left[0-70 \%\left(\mathrm{NH}_{4}\right)_{2} \mathrm{SO}_{4}\right.$; Sephadex G-25] from Berberis aggregata $(1.1 \mathrm{mg} / \mathrm{ml}$ protein). (R)-Tetrahydrojatrorrhizine was taken as control.

enzymes involved in the formation of berberine from $(S)$-reticuline. The chain of reactions starting from dopamine and 3,4-dihydroxyphenylacetaldehyde and leading to berberine is shown in Figure 5. Some properties of the eight enzymes, seven of which have been discovered and characterized in our laboratory, are shown in Table 2. Berberine is used medicinally, especially in East Asia. It is the first alkaloid whose biosynthesis is now completely understood at the enzyme level.

COMPARTMENTATION.-Homogenizing cultured cells of the genus Berberis in phosphate buffer results in a soluble enzyme preparation, containing all eight of the above-described enzymes of the berberine pathway. Using a gentle cell disintegration method with an isotonic sucrose-containing buffer and subjecting this preparation to sucrose density ultracentrifugation, and subsequently analyzing the gradient for activity of the individual enzymes, Amann et al. demonstrated (27) that only six of the enzymes were indeed soluble, while two of them (BBE and STOX) were found in one and the same particle fraction showing a buoyant density of $\rho=1.14 \mathrm{~g} / \mathrm{cm}^{3}$. Figure 7 shows a typical fractionation profile, illustrating the separation of organelles and indicating the position of marker enzymes for organelles. By electron microscopy, this fraction was seen to be predominantly composed of smooth vesicles (27). Freezing and thawing of this preparation liberated both enzymes and rendered them completely soluble. Analysis of the protein composition of this preparation by SDS-gel electrophoresis revealed the presence of only about ten separable proteins, of which two major ones are BBE and STOX. By immunoelectrophoresis it could be demonstrated that STOX is exclusively located in these vesicles. Incubation of these vesicles with the substrate $(S)$-reticuline in the presence and absence of $S$-adenosyl-L-methionine in both cases led to the formation of a red product identified as dehydroscoulerine. This fact indicates that no methyl- 


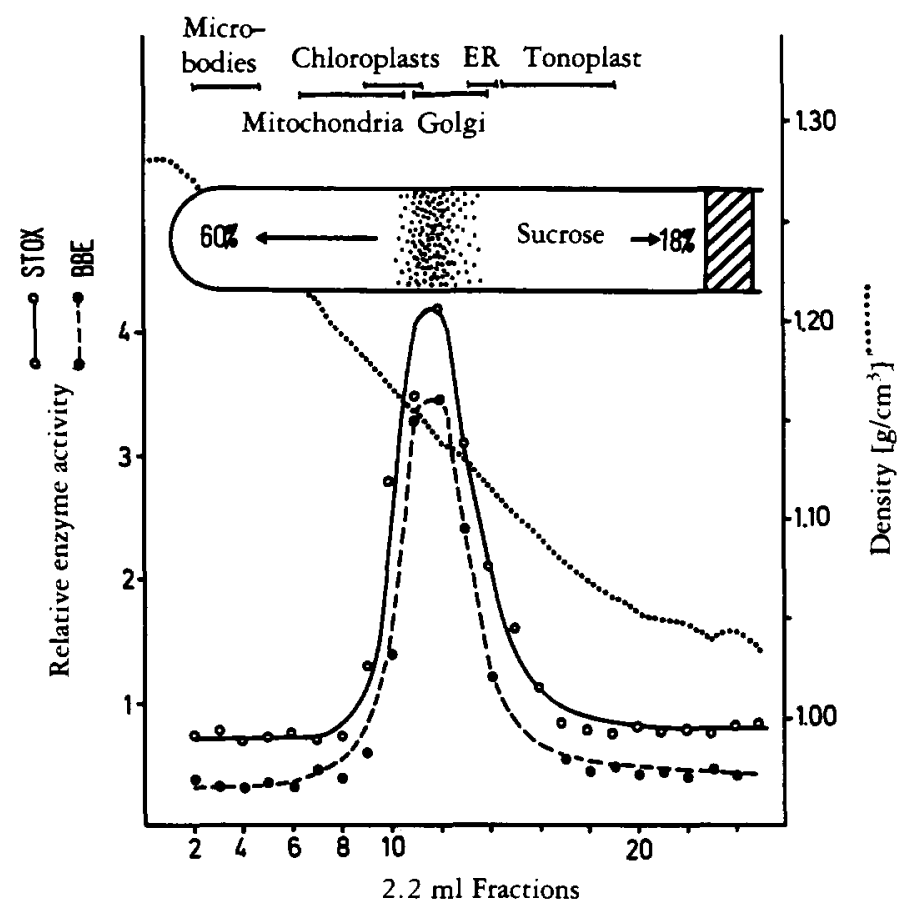

FIGURE 7. Typical fractionation profile of a sucrose density gradient separation of organelles isolated from Berberis wilsoniae var. subcaulialata. BBE and STOX enzyme activity were localized exclusively with matching peaks at a density of $\delta=1.14 \mathrm{~g} /$ $\mathrm{cm}^{3}$.

transferase is located in the vesicles. If the cytoplasmic enzyme $S$-adenosyl-Lmethionine:(S)-scoulerine-9-O-methyltransferase is added to this smooth vesicle preparation, in the presence of $(S)$-reticuline and SAM, no dehydroscoulerine, but rather columbamine, is formed (Table 3). Columbamine is the immediate precursor of berberine (26).

Finally, addition of soluble berberine synthase enzyme to the vesicles that are synthesizing columbamine leads predominantly to the formation of berberine. The cooperation of vesicular and cytoplasmic enzymes therefore leads to berberine, a late product of this biosynthetic branch. The isolated vesicles are yellow. Analysis of the pigments demonstrated that the vesicles contained protoberberine alkaloids in the same ratio as is found in the cultivated cells. These vesicles have been found in members of four different plant families: Annonaceae, Berberidaceae, Ranunculaceae, and Menispermaceae, in cell cultures as well as in differentiated tissue. These vesicles are the first highly specific and unique compartment serving only for alkaloid biosynthesis. From a regulatory point of view, the vesicles must play a major role in determining the direction of biosynthesis. Reticuline (Figure 1) can be transformed to a multitude of isoquinoline structures even within one and the same cell culture (6). Once a molecule of $(S)$-reticuline enters a vesicle, however, its further metabolic fate is immediately determined. The exclusive occurrence of $\mathrm{BBE}$ within the vesicles will transform the precursor molecule reticuline, to scoulerine, which means that only a protoberberine structure can result as a consequence of this entry. Scoulerine, now possessing the berberine bridge, can leave the vesicle and be further methylated or transformed in other ways. Reentry of the modified molecule into the vesicle will yield oxidized protoberberines (e.g., columbamine), which can undergo further metabolism to berberine, and opening of the methylenedioxy ring (7) will eventually lead to jatrorrhizine, the major sec- 
TABLE 3. In Vitro Transformation of Labeled Reticuline by Vesicles Cooperating with Cytoplasmic Enzymes

\begin{tabular}{l|r|r|r}
\hline \multirow{2}{*}{\multicolumn{1}{c|}{ Alkaloid formed }} & \multicolumn{2}{|c}{ Relative amount of alkaloids (\%) } \\
\cline { 2 - 4 } & \multicolumn{3}{|c}{ Sample number } \\
\cline { 2 - 4 } & $1^{\mathrm{b}}$ & $2^{\mathrm{c}}$ & $3^{\mathrm{d}}$ \\
\hline Reticuline $^{\mathrm{e}}$ & 41 & 37 & 11 \\
Dehydroreticuline $_{\text {Scoulerine }}$ & 0 & 0 & 0 \\
Dehydroscoulerine & 20 & 8 & 0 \\
Tetrahydrocolumbamine & 39 & 0 & 0 \\
Columbamine & 0 & 0 & 0 \\
Canadine & 0 & 55 & 40 \\
Berberine & 0 & 0 & 0 \\
& 0 & 0 & 49 \\
\hline
\end{tabular}

${ }^{a}$ All three samples $(0.5 \mathrm{ml}, 14 \%$ sucrose) contained $0.01 \mathrm{mM}$ $\left[{ }^{14} \mathrm{C}-\mathrm{N}\right]-(S)$-reticuline $(0.3 \mu \mathrm{Ci}), 0.2 \mathrm{mM} S \mathrm{SAM}$ and $0.1 \mathrm{ml}$ purified vesicles $(0.02 \mathrm{mg}$ protein containing 5 pkat BBE and 22 pkat STOX) in tricine gradient buffer.

bSample 1 was incubated without further additions.

'Cytoplasmic $S$-adenosyl-L-methionine: $(S)$-scoulerine-9-O-methyltransferase (22.5 pkat) was added to sample 2 .

'Sample 3 contained 0.01 pkat of berberine synthase besides the methyltransferase. After $10 \mathrm{~h}$ incubation at $30^{\circ}$ the alkaloids were extracted and identified by tlc in two solvent systems.

'Residual amount.

ondary metabolite of Berberis cell cultures. Thus, the number of vesicles, their location within the cytoplasm of the cell, and possibly an active or even passive uptake system for reticuline within the vesicle membrane will determine the amount of cytoplasmic $(S)$-reticuline that will be transformed into protoberberines.

VACUOLAR STORAGE. - It is now general knowledge that alkaloids are accumulated and stored within plant vacuoles. The question remains how the isoquinoline alkaloids that are formed in the cytoplasm (with or without participation of vesicles) are finally deposited in the vacuole. The transport of alkaloids from the cytosol across the vacuolar membrane- the tonoplast - into the vacuole is crucial for the storage of alkaloids in the vacuolar space. A simple model for alkaloid accumulation in vacuoles of plant cells is based on the fact that vacuolar cell sap is acidic. According to this model, alkaloids can freely pass through the tonoplast by diffusion in their lipophilic forms. In the acidic vacuole, they are protonated and therefore trapped as cations to which the tonoplast is not permeable; see literature cited by Deus-Neumann and Zenk (28). This phenomenon has been called the "ion-trap mechanism." Doubts about this ion-trap mechanism arose when we could demonstrate $(29,30)$ that isolated vacuoles of an alkaloid-containing plant take up only those alkaloids that are indigenous to the plant species from which the vacuoles had been isolated. Vacuoles of alkaloid-free plants did not take up any alkaloids. Vacuolar alkaloid transport was characterized as an active, probably energy-requiring mechanism (30). For a further characterization of this transport system, isolated vacuoles from Fumaria capreolata cell cultures were used. The differential uptake of two alkaloids, reticuline and scoulerine, in both their $(S)$ - and $(R)$ configurations, was investigated (28). It was demonstrated that the uptake of alkaloids is carrier-mediated, as shown by its substrate saturation and its sensitivity to metabolic inhibitors. Most interestingly, however, only the $(S)$-forms of reticuline and scoulerine were taken up, while the $(R)$-enantiomers, which do not occur in this plant species, 
were strictly discriminated against (Figure 8). Saturation of the uptake system is achieved with a concentration of ca. $0.5 \mu \mathrm{M}(S)$-reticuline in the incubation medium. The $\mathrm{K}_{\mathrm{M}}$-value for the uptake is calculated as $0.3 \mu \mathrm{M}$ and was exactly in the range of

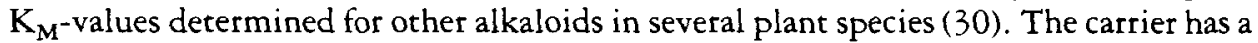
high affinity for the substrate, and the transport was stimulated sevenfold by ATP. As shown in Table 4, this stimulation of $(S)$-reticuline uptake into Fumaria vacuoles is highly specific for ATP; none of the other nucleotide triphosphates, as well as ADP, AMP, or adenosine, stimulate this vacuolar transport. In addition, evidence was found,

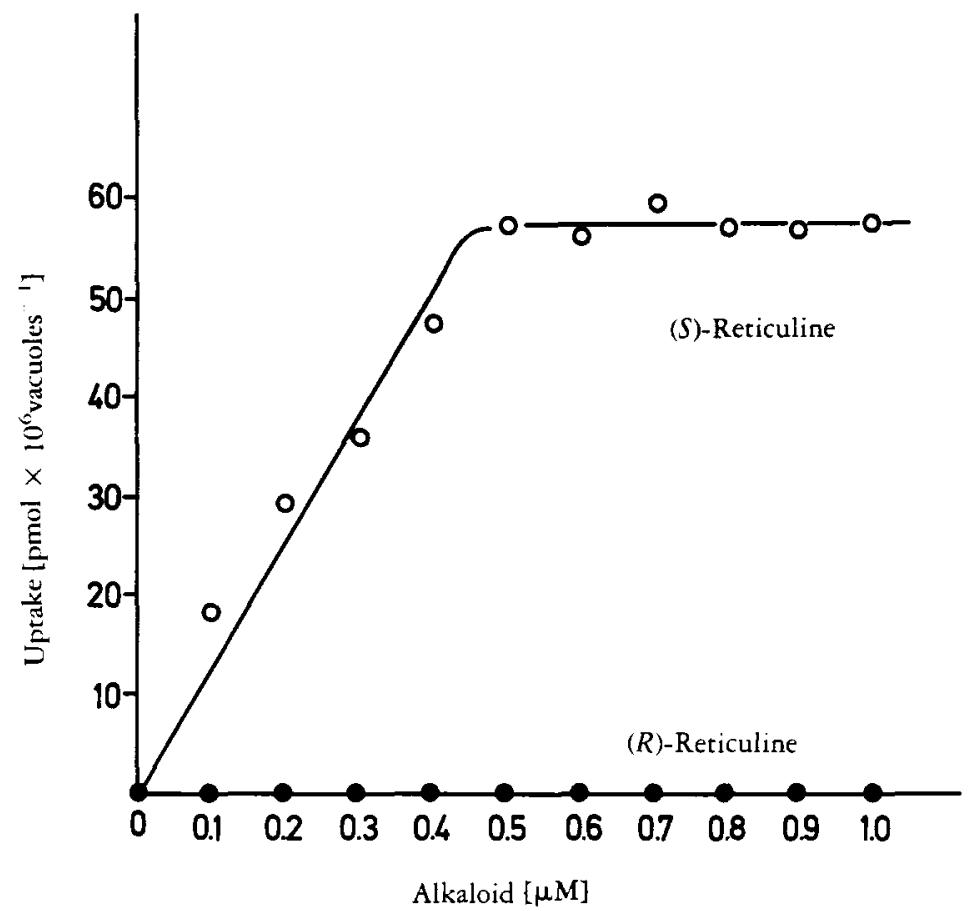

FIGURE 8. Uptake of $(S)$-reticuline and $(R)$-reticuline by isolated vacuoles of Fumaria capreolata as a function of concentration. The alkaloid uptake was determined after $40 \mathrm{~min}$ of incubation using enantiomer specific radioimmunoassays, substracting the endogeneous $(S)$-reticuline level of the vacuoles.

using ATPase inhibitors and proton gradient dissipators, that vacuolar alkaloid transport follows a proton-antiport mechanism. Efflux experiments with vacuoles preloaded with labeled $(S)$-reticuline proved that alkaloid unloading of the vacuoles is also highly specific and energy dependent. The data now accumulated present clear evidence that alkaloids are readily channeled in and out of the vacuole by energy-dependent carriermediated transport. Very probably, the same carrier mediates transport in both directions, and there is no doubt about the energization of the transport process. The iontrap mechanism is therefore no longer tenable for the explanation of alkaloid accumulation in plant vacuoles.

Alkaloid transport through the tonoplast membrane proceeds neither by diffusion nor by a channel protein mechanism. Evidence is now accumulating (28-30) that for every alkaloid there is a highly specific alkaloid carrier or specific binding site of a general carrier present in the tonoplast membrane. A working model showing the possible mechanism by which alkaloids are transported into and out of vacuoles is shown in Figure 9 . This model agrees in principle with the hypothesis developed for general product transport in plant vacuoles $(31,32)$. 
TABLE 4. Uptake of (S)-Reticuline by Isolated Vacuoles of Fumaria capreolata as Affected by ATP and Different Cofactors

\begin{tabular}{l|c|r}
\hline \hline \multirow{2}{*}{ Compound added } & \multicolumn{2}{|c}{$(S)$-Reticuline uptake } \\
\cline { 2 - 3 } & $\begin{array}{c}\text { pmol } \\
\left(10^{6} \text { vacuoles }^{-1}\right)\end{array}$ & $\begin{array}{c}\text { control } \\
(\%)\end{array}$ \\
\hline (0 mM) & 37.1 & 15 \\
ATP $(0.5 \mathrm{mM})$ control & 253.0 & 100 \\
Adenosine $(0.5 \mathrm{mM})$ & 29.0 & 12 \\
AMP $(0.5 \mathrm{mM})$ & 11.5 & 5 \\
ADP $(0.5 \mathrm{mM})$ & 15.1 & 6 \\
CTP $(0.5 \mathrm{mM})$ & 20.2 & 8 \\
GTP $(0.5 \mathrm{mM})$ & 29.9 & 12 \\
ITP $(0.5 \mathrm{mM})$ & 35.4 & 14 \\
UTP $(0.5 \mathrm{mM})$ & 81.0 & 32 \\
\hline
\end{tabular}

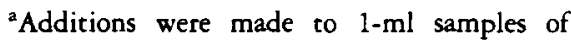
Fumaria vacuole suspension $\left(4.5 \times 10^{5} / \mathrm{ml}\right)$ prior to the addition of $\left[{ }^{3} \mathrm{H}\right\}-(S)$-reticuline $(500 \mathrm{pmol} / \mathrm{ml})$. Incubation of all samples was terminated after 40 min by filtration centrifugation.

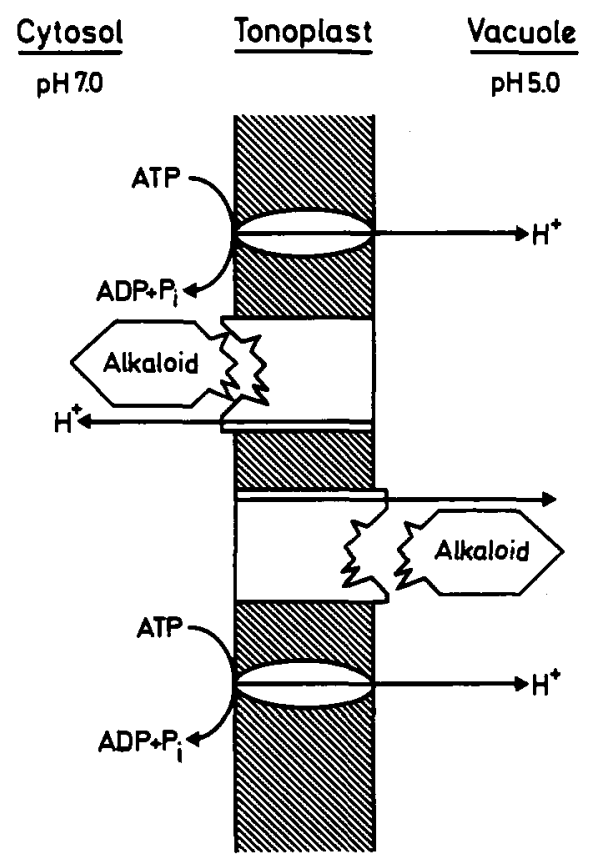

FIGURE 9. Working model showing the function of $\mathrm{H}^{+}$. translocating ATPase in a highly specific alkaloid transport system in the tonoplast membrane.

CONCLUSIONS. - We may infer from the above findings that, in general, studies involving labeled precursors, using differentiated plants or even using crude, unpurified enzyme extracts, have not led to the true sequence of biosynthetic events. Enzymatic work, purification, and characterization of the enzymes involved, as well as 
studies about their compartmentation will lead to the knowledge of how secondary products are formed, transported, and stored in plants. For a few groups of alkaloids, we can now imagine nature's fascinating strategy in secondary plant product biosynthesis at that level; these are the indole alkaloids (33), the quinolizidine alkaloids (34), and the protoberberine alkaloids shown here. Looking at the rapidly developing and commercially attractive field of gene technology, we should remember that unless we know the gene products (meaning the particular enzymes of secondary pathways), we will be able neither to understand the metabolic sequences leading to natural products, nor to locate and isolate the genes responsible for the synthesis of the respective enzymes. Considering the magnificent application fundamental and industrial research has found for microbial genes, we should keep in mind that there are only about 3000 bacterial and 60,000 fungal species known up to now, in contrast to the existence of more than 370,000 plant species (35), plants which are filled with enormous numbers of highly diverse secondary product types serving many allelochemical functions. This tremendous gene pool within the plant kingdom, producing enzymes catalyzing the most remarkable chemical reactions, has not yet been touched. It will be the responsibility of plant scientists to develop our knowledge about secondary pathways, which will ultimately lead us to the genes involved in the synthesis of secondary products and to the broad field of biotechnological application of this knowledge.

\section{ACKNOWLEDGMENTS}

Linguistic help by Dr. Bruce Cassels during the preparation of this manuscript is gratefully acknowledged. This work was supported by SFB 145 of the Deutsche Forschungsgemeinschaft, Bonn, and by the Fonds der Chemischen Industrie.

\section{LITERATURE CITED}

1. M. Shamma, The Isoquinoline Alkaloids, Academic Press, New York, 1972.

2. M. Shamma and J.L. Moniot, Isoquinoline Alkaloid Research 1972-1977, Plenum Press, New York, 1978.

3. G.A. Cordell, Introduction to Alkaloids, John Wiley, New York, 1981.

4. I.D. Spencer, in: Comprehensive Biochemistry, 20, 231 (1968).

5. M. Rueffer, in: The Chemistry and Biology of lsoquinoline Alkaloids, Ed. by J.D. Phillipson, et al., Springer, Heidelberg, 1985, p. 265.

6. T. Tanahashi and M.H. Zenk, Plant Cell Rep., 4, 96 (1985).

7. M.H. Zenk, in: The Chemistry and Biology of Isoquinoline Alkaloids, Ed. by J.D. Phillipson, et al., Springer, Heidelberg, 1985, p. 240.

8. W.J. Kelleher, A. Rother, E. Wellmann, H. Grisebach, Planta Med. 40, 127 (1980).

9. E. Winterstein and G. Trier, Die Alkaloide, Gebrüder Bornträger, Berlin, 1910.

10. J.R. Gear and I.D. Spenser, Nature, 191, 1393 (1961).

11. H.L. Holland, P.W. Jeffs, T.M. Capps, and D.B. MacLean, Can.J.Chem., 57, 1588 (1979).

12. M.L. Wilson and C.J. Coscia, J.Am.Chem.Soc, 97, 431 (1975).

13. H.M. Schumacher, M. Rueffer, N. Nagakura, and M.H. Zenk, Planta Med., 48, 212 (1983).

14. H. Hinz and M.H. Zenk, Naturwissenschaften, 67, 620 (1981).

15. E. Späth and F. Kuffner, Chem.Ber., 64, 370 (193i).

16. T.M. Kutchan, S. Ayabe and C.J. Coscia, in: The Chemistry and Biology of Isoquinoline Alkaloids, Ed. by J.D. Phillipson, et al., Springer, Heidelberg, 1985 (and literature cited therein), p. 281.

17. M. Rueffer and M.H. Zenk, manuscript in preparation.

18. M. Rueffer, H. El-Shagi, N. Nagakura, and M.H. Zenk, FEBS Lett., 129,5 (1981).

19. M. Rueffer, N. Nagakura, and M.H. Zenk, Planta Med., 49, 131 (1983).

20. C.K. Wat, P. Steffens, and M.H. Zenk, in press (1986).

21. E. Rink and H. Böhm, FEBS Lett., 49, 396 (1975).

22. P. Steffens, N. Nagakura, and M.H. Zenk, Phytochemistry, in press (1985).

23. S. Muemmler, M. Rueffer, N. Nagakura, and M.H. Zenk, Plant Cell Rep., 4, 36 (1985)

24. M. Amann, N. Nagakura, and M.H. Zenk, Tetrabedron Lett., 25, 953 (1984).

25. C.W.W. Beecher and W.J. Kelleher, Tetrabedron Lett., 25, 4595 (1984).

26. M. Rueffer and M.H. Zenk, Tetrabedron Lett., 26, 201 (1985).

27. M. Amann, G. Wanner, and M.H. Zenk, Planta, (in press). 
28. B. Deus-Neumann and M.H. Zenk, Planta, (in press).

29. B. Deus and M.H. Zenk, Biotechn.Bioeng., 24, 1965 (1982).

30. B. Deus-Neumann and M.H. Zenk, Planta, 162, 250 (1984).

31. H. Sze, Pbysiol.Plantarum, 61, 683 (1984).

32. C. Werner and P. Matile, J.Plant Pbysiol., 118, 237 (1985).

33. J. Stöckigt, in: Indole and Biogenetically Related Alkaloids, Ed. by J.D. Phillipson and M.H. Zenk, Academic Press, London, 1980.

34. M. Wink and T. Hartman, in: Natural Products Chemistry 1984, Elsevier Science Publishers, Amsterdam, 1984, p. 511.

35. D. von Denffer, F. Ehrendorfer, K. Mägdefrau, and H. Ziegler, Lebrbucb der Botanik, Fischer, Stuttgart, 1978. 